\title{
D-galactose induces astrocytic aging and contributes to astrocytoma progression and chemoresistance via cellular senescence
}

\author{
JINGANG HOU $^{1 *}$, YEEJIN YUN ${ }^{2 *}$, JIANJIE XUE ${ }^{3,4}$, MENGQI SUN ${ }^{5}$ and SUNCHANG KIM ${ }^{1,2}$ \\ ${ }^{1}$ Intelligent Synthetic Biology Center; ${ }^{2}$ Department of Biological Sciences, KAIST, Daejeon, South Chungcheong 34141 , \\ Republic of Korea; ${ }^{3}$ Qingdao Municipal Center for Disease Control and Prevention; ${ }^{4}$ Qingdao Institute of Preventive \\ Medicine, Qingdao, Shandong 266033; Jilin Academy of Agricultural Sciences, Changchun, Jilin 130033, P.R. China
}

Received March 14, 2019; Accepted August 23, 2019

DOI: $10.3892 / \mathrm{mmr} .2019 .10677$

\begin{abstract}
The administration of D-galactose triggers brain aging by poorly understood mechanisms. It is generally recognized that D-galactose induces oxidative stress or affects protein modifications via receptors for advanced glycated end products in a variety of species. In the present study, we aimed to investigate the involvement of astrocytes in $\mathrm{D}$-galactose-induced brain aging in vitro. We found that D-galactose treatment significantly suppressed cell viability and induced cellular senescence. In addition, as of the accumulation of senescent cells, we proposed that the senescence-associated secretory phenotype (SASP) can stimulate age-related pathologies and chemoresistance in brain. Consistently, senescent astrocytic CRT cells induced by D-galactose exhibited increases in the levels of IL-6 and IL-8 via NF- $\kappa$ B activation, which are major SASP components and inflammatory cytokines. Conditioned medium prepared from senescent astrocytic CRT cells significantly promoted the viability of brain tumor cells (U373-MG and N2a). Importantly, conditioned medium greatly suppressed the cytotoxicity of U373-MG cells induced by temozolomide, and reduced the protein expression levels of neuron marker neuron-specific class III $\beta$-tubulin, but markedly increased the levels of c-Myc in N2a cells. Thus, our findings demonstrated that D-galactose treatment might mimic brain aging, and that $\mathrm{D}$-galactose could contribute to brain inflammation and tumor progression through inducing the accumulation of senescent-secretory astrocytes.
\end{abstract}

Correspondence to: Professor Sunchang Kim, Department of Biological Sciences, KAIST, 291 Daehak-ro, Yuseong-gu, Daejeon, South Chungcheong 34141, Republic of Korea

E-mail: sunkim@kaist.ac.kr

${ }^{*}$ Contributed equally

Key words: D-galactose, astrocytic CRT cells, senescence, brain tumor, chemoresistance

\section{Introduction}

Cellular senescence was originally reported as definite proliferative capacity in human fibroblasts culture, which reflects one particular type of senescence produced by the absence of endogenous telomere activities (1). Apart from telomere erosion, various noxious stimuli such as DNA lesions and reactive oxygen species (ROS) have also been shown to induce a senescent growth arrest in vitro (2-5). Cellular senescence was originally proposed to prevent the growth of damaged cells, indicating a safeguard against cancer (6,7). Subsequent studies during past decades convincingly demonstrated that senescent cells are involved in aging, aging-related dysfunction and chronic diseases $(8,9)$. Intriguingly, senescent cells have a complex senescence-associated secretory phenotype (SASP). SASPs were postulated that they contributed to the development and processing of age-associated pathologies including malignant transformation by changing tissue microenvironment (10-12).

In the brain, the aging process is associated with neuronal degeneration and loss, which eventually lead to cognitive impairment. Thus, aging is widely recognized as one the most prominent risk factors for Alzheimer Disease (AD). Brain aging is typically accompanied with the suppression of innate immunity, favoring a pro-inflammatory status (13). Astrocytes in aging brains can trigger SASP, presenting a typical proinflammatory phenotype, suggesting that senescent astrocytes drives a low-level, chronic inflammatory status in aged brains (14). Therefore, models of senescence may permit investigations into potential cellular mechanisms of astrocytic senescence, in which treatments for delaying or preventing brain aging and aging-related neuroinflammation or subsequent degeneration could be developed.

Chronic low dose D-galactose treatment leads to accelerated aging in rodent and Drosophila models. Interestingly, rodents chronically treated with D-galactose showed progressive decline in learning and memory abilities, neurodegeneration and a damaged immune system (15-17). Drosophila models exhibited shortened lifespans and increasing oxidative stress. While D-galactose-induced models have been widely reported for the study of brain aging processes and drug 
candidate screening, how galactose affects organismal brain aging remains unclear. In the present study, we report evidence indicating D-galactose-induced astrocytic senescence.

\section{Materials and methods}

Reagents and cell culture. D-galactose and Bay 11-7082 were purchased from Sigma-Aldrich (Merck KGaA). Astrocytic CRT and U373-MG Uppsala cells (kindly provided by Professor Chul-hee Choi, Korea Advanced Institute of Science and Technology, South Korea) were maintained in RPMI-1640 medium (Thermo Fisher Scientific, Inc.) with $10 \%$ heat-inactivated fetal bovine serum (FBS), $100 \mathrm{U} / \mathrm{ml}$ of penicillin, and $100 \mu \mathrm{g} / \mathrm{ml}$ of streptomycin (Thermo Fisher Scientific, Inc.) as previously described (18). N2a cells (ATCC ${ }^{\circledast}$ CCL-131 ${ }^{\mathrm{TM}}$ ) were grown in Dulbecco's Modified Eagles medium (DMEM; Thermo Fisher Scientific, Inc.) supplemented with 1 or $10 \%$ heat-inactivated FBS (Thermo Fisher Scientific, Inc.), $100 \mathrm{U} / \mathrm{ml}$ of penicillin and $100 \mu \mathrm{g} / \mathrm{ml}$ of streptomycin. Primary rat astrocytes were maintained in 10\% FBS-DMEM containing $1 \%$ nonessential amino acids (Gibco; Thermo Fisher Scientific, Inc.). Stable cell line CRT-MG/IL-8p-d2EGFP cells were prepared and maintained as previously described (19). All the cells were incubated at $37^{\circ} \mathrm{C}$ in a $5 \% \mathrm{CO}_{2}$ atmosphere.

Senescence induction and senescence-associated $\beta$-galactosidase (SA- $\beta$-gal) staining. Human astrocytic CRT cells and rat primary astrocytes were treated with varying doses of D-galactose resolved in culture medium (0-60 g/l) at $37^{\circ} \mathrm{C}$ and the cell viability after $72 \mathrm{~h}$ exposure was determined. The half-maximal inhibitory concentration, $50 \mathrm{~g} / 1$, of D-galactose was used for the subsequent experiments. SA- $\beta$-gal staining was performed using an SA- $\beta$-gal kit (cat. no. 9860, Cell Signaling Technology, Inc.) in accordance with the manufacturer's protocols to confirm cellular senescence. The cells were fixed for 10-15 min at room temperature, then rinsed twice with PBS and stained with staining solution at a final $\mathrm{pH}$ of 6.0 overnight. The SA- $\beta$-gal-positive cells were seen as blue, and were counted under a phase-contrast microscope (magnification, x 100; 5 fields per view analyzed). The experiment was repeated three times in each group.

Cell viability assay. Cell viability was evaluated by a WST-1 assay, which is based on the enzymatic cleavage of the tetrazolium salt WST-1 to formazan by cellular mitochondrial dehydrogenase present in viable cells. In brief, after $24 \mathrm{~h}$ following treatment, $20 \mu \mathrm{l}$ of WST-1 was added to each well (12-well plate with $1 \times 10^{5}$ cells per well) and the plates were incubated at $37^{\circ} \mathrm{C}$ for $2 \mathrm{~h}$. The plates were employed for centrifugation $(300 \mathrm{x} \mathrm{g})$ at room temperature for $3 \mathrm{~min}$ and $100 \mu \mathrm{l}$ of the medium was withdrawn and analyzed by measuring the absorbance at a wavelength of $450 \mathrm{~nm}$ using microplate reader (Tecan Group, Inc.).

Preparation of conditioned medium (CM) from CRT cells. Astrocytic CRT cells ( $8 \times 10^{5}$ cells in $90 \mathrm{~mm}$ petri dish) were exposed to D-galactose $(50 \mathrm{~g} / \mathrm{l})$ at $37^{\circ} \mathrm{C}$ for 10 days to induce premature secretory senescence. Then, 8 days following senescence induction, cells were cultured with complete culture medium (without 10\% FBS) for the collection of CM. The CM was collected from both pre-senescent (untreated cells) and senescent cells after $48 \mathrm{~h}$. CM were centrifuged for $20 \mathrm{~min}$ at $800 \mathrm{x} \mathrm{g}$ at $4^{\circ} \mathrm{C}$, filtered through $0.22 \mu \mathrm{m}$ bottle-top filters (Sartorius Stedim Biotech) and used for subsequent experiments. CM was used to treat U373-MG and N2a cells with different percentages $(25,50$, and $100 \%)$ at $37^{\circ} \mathrm{C}$ for $24 \mathrm{~h}$. Cells were then exposed with or without $0.5 \mathrm{mM}$ Temozolomide (TMZ, Sigma-Aldrich; Merck KGaA) at $37^{\circ} \mathrm{C}$ for $48 \mathrm{~h}$ followed by cell viability tests using the WST-1 method and observations of morphological changes by microscopy (magnification, $\mathrm{x} 100$; 6 fields per view analyzed).

Interleukin (IL)-6 and IL-8 levels in the CM were quantified using the Human IL-6 and IL-8 ELISA kits (cat. nos. D6050 and D8000C, R\&D Systems, Inc.) according to the manufacturer's protocols. Briefly, $100 \mu \mathrm{l}$ of culture media normalized by cell number was added in the wells with five replicates and incubated for $2.5 \mathrm{~h}$ at room temperature with gentle agitation. Then, the medium was discarded and wells were washed with washing buffer for four times. After that, $100 \mu \mathrm{l}$ of human IL-6 or IL-8 conjugate were added to each well and plates was incubated for $2 \mathrm{~h}$ at room temperature with gentle agitation. Following washing with washing buffer, $100 \mu \mathrm{l}$ of substrate solution was added to each well and incubated for $20 \mathrm{~min}$ at room temperature. Lastly, $50 \mu 1$ of stop solution was added and wells were assayed with a microplate reader set to $450 \mathrm{~nm}$ within $30 \mathrm{~min}$.

Immunoblotting. Whole cell lysate $(20 \mathrm{mg})$ was prepared from various treatments. The samples ( $30 \mu \mathrm{g}$ determined by Bradford Assay) were loaded onto $10 \%$ SDS-PAGE and separated by electrophoresis for $2 \mathrm{~h}$ at $100 \mathrm{~V}$. Protein were transferred polyvinylidene difluoride membrane for $1 \mathrm{~h}$ at $110 \mathrm{~V}$. The following primary antibodies were used: Antibody p16ink4a, p53, p21, PARP, Cleaved caspase 3, c-Myc and Tju1 (rabbit polyclonal, 1:2,000, Abcam, cat. nos. ab51243; ab32389; ab109520; ab74290; ab2302; ab39688 and ab18207, respectively); senescence marker protein 30 (SMP30; mouse monoclonal, 1:1,000, Santa Cruz Biotechnology, Inc., cat. no. sc-390098), GAPDH as a loading control (mouse monoclonal, 1:4,000, Santa Cruz Biotechnology, Inc., cat. no. sc-47724). Membranes were washed and incubated with horseradish peroxidase-conjugated secondary antibodies (1:5,000; Cell Signaling Technology, Inc., cat. nos. sc-2370 and sc-2380). The bands from the western blots were densitometrically visualized by ECL detection and the signals quantified using ImageJ software (version 1.5.1, National Institutes of Health).

For the immunofluorescence assay, the cells were first washed twice with PBS, then fixed with $4 \%$ paraformaldehyde for $15 \mathrm{~min}$ and permeabilized with buffer $(0.15 \%$ Triton X-100 in PBS) for $20 \mathrm{~min}$ at room temperature. Cells were blocked with $3 \%$ bovine serum albumin (Sigma-Aldrich; Merck $\mathrm{KGaA}$ ) for $30 \mathrm{~min}$ and then incubated with primary antibodies against NF- $\kappa$ B p65 (rabbit polyclonal, 1:200, Santa Cruz Biotechnology, Inc., cat.no. sc-8008), and IL-6 (mouse monoclonal, 1:1,000, Abcam) overnight at $4^{\circ} \mathrm{C}$. Following washing three times for 5 min each with PBS and 0.05\% Triton X-100. Cells were incubated with appropriate Alexa Fluor ${ }^{\circledR}$ secondary antibodies 488 or 594 (Invitrogen; Thermo Fisher Scientific, Inc., cat. nos. A-11008; A21209) to detect the signal at room temperature for $1.5 \mathrm{~h}$. After another set of washing, images 
were captured with a Nikon i2 U fluorescence microscope (magnification, x100; Nikon Corporation).

Optical density analysis was conducted to quantify the fluorescence signal and was performed by using CellProfiler Software (2.2.0, https://cellprofiler.org). Each evaluation was conducted on five fields randomly selected for each of the target proteins.

Statistical analysis. All data were expressed as the mean \pm standard deviation except unless otherwise indicated. P-values were generate using a Student's t-test or one-way analysis of variance; $\mathrm{P}<0.05$ was considered to indicate a statistically significant difference. A protected Fisher's Least Significant Difference post hoc test was used for multiple comparisons. All calculations were performed using GraphPad Prism software (v7.0, GraphPad Software, Inc.).

\section{Results}

D-galactose induces the senescence of astrocytic CRT cells and rat primary astrocytes. To determine whether D-galactose can induce the senescence of astrocytic cells, we first cultured astrocytic CRT cells and rat primary astrocytes in the absence or presence of varying doses of D-galactose (0-60 g/l) and observed the cell viability after $72 \mathrm{~h}$ treatment (Fig. 1A). Treatment with D-galactose significantly suppressed cellular viability in a dose-dependent manner from $40 \mathrm{~g} / \mathrm{l}$ of D-galactose upwards. Importantly, a higher dose of D-galactose $(60 \mathrm{~g} / \mathrm{l})$ induced a considerable cell death (profound apoptotic bodies) as observed under microscopy. Then, we investigated further the classic markers of the senescence-related phenotype. The astrocytic CRT and rat primary cells exhibited flattened morphology and significantly increased levels of SA- $\beta$-gal activity compared with the control (Fig. 1B). Additionally, the expression of hallmark regulatory proteins, such as p16, p53, p21 and SMP30 were markedly elevated after D-galactose exposure (Fig. 1C). Taken together, these observations demonstrated that, in a relative long-term of 3 days with D-galactose, astrocytic cells were susceptible to the stress, thereby inducing a characteristic senescent phenotype.

Senescent astrocytic CRT cells develop the SASP phenotype. Since the treatment of D-galactose induced typical the senescent phenotype in CRT cells, we next examined at the intracellular level the expression of proinflammatory cytokines IL-6 and IL-8, the major SASP components in rodent and human cells (20). As expected, D-galactose significantly increased IL-6 expression by astrocytic CRT-cells compared with the control (Fig. 2A). In addition, significantly increased IL-8 expression at the transcriptional level was also exhibited by the stable cell line CRT-MG/IL-8p-d2EGFP cells compared with the control (Fig. 2B). To explore the molecular mechanism, we examined the expression of NF- $\mathrm{NB}$ by immunofluorescence, which has been revealed to stimulate the transcription of many SASP genes (10), and the results indicated a significant increase in the nuclear translocation after D-galactose exposure compared with the control (Fig. 2C). Our findings suggested that D-galactose increased the expression of SASP-related proteins through activating the NF- $\mathrm{NB}$ pathway as early as 6 days after treatment as determined by elevated secretions of IL-6 and IL-8, which was abrogated by a NF- $\kappa$ B pathway inhibitor, Bay 11-7082 (Fig. 2D), suggesting that it may act as a potential target for inhibition on development of SASP in astrocytes.

CM from senescent astrocytes promotes brain tumor cell viability and survival from chemotherapy agent treatment. To explore the role of CM in the process of cellular senescence, we used two different brain tumor cell lines: U373-MG and N2a. CM was used to treat U373-MG and N2a cells at various concentrations (25-100\% of culture medium; Fig. 3A and D). Treatment of U373-MG and N2a cells (with 10\% FBS) promoted cell viability, suggesting a pro-tumoral action. Furthermore, U373 cells treated with different concentrations of CM were exposed to $0.5 \mathrm{mM}$ temozolomide, and strong chemotherapy resistance was observed with sustained cell viability compared with the control treated with temozolomide (Fig. 3B). This resistance was further confirmed by the decreased levels of activated apoptosis-associated molecules cleaved caspase-3 and PARP (Fig. 3C). Intriguingly, N2a cell-derived neurons (with $1 \%$ FBS) were observed as tumor-like neuroblasts after treatment with $\mathrm{CM}$. The results herein showed that neuron-specific class III $\beta$-tubulin expression levels were markedly decreased, and tumor-like alterations were observed with reduced dendritic extensions. In addition, we also observed the increased expression of c-Myc protein (Fig. 3E), which is important for cancer cell proliferation (21). Therefore, these studies suggest a potential key role of CM derived from senescent astrocytic cells in human brain tumor progression.

\section{Discussion}

Our findings suggest that treatment with D-galactose might induce astrocytic cellular senescence and promote brain aging pathologies, including the onset of brain cancer by the mechanism that comprises the SASP. Senescent cells are not limited to irreversible cell-cycle arrest. Of note, senescent cells have undergone various changes in protein expression and secretion, ultimately leading to SASP(11). Coppe et al (22), Orjalo et al (23) and Davalos et al (24) first discovered that senescent cells could trigger tumorigenesis in neighboring malignant cells, and disrupt normal tissue structure and function. Additionally, the accumulation of senescent cells after chemotherapy gives rise to chemoresistance and cancer recurrence (25). Our study proposed that senescent astrocytes induced by D-galactose develop SASP via activating the $\mathrm{NF}-\kappa \mathrm{B}$ pathway, suggesting a potential mechanism of cellular senescence in the normal brain aging process.

Of note, low-dose administration of D-galactose is a widely recognized model for brain aging in rodents. Increasing evidence has been reported that D-galactose treatment induces memory impairment, synaptic dysfunction, oxidative stress and neurodegeneration $(26,27)$; however, little is known about the underlying mechanism. Elevated levels of D-galactose trigger ROS accumulation in the brain, ultimately inducing oxidative stress and the production of advanced glycation end products (AGEs). These changes have been shown to be involved in physiologically aging and in neurodegenerative diseases, such as AD and Parkinson's disease, indicated by the 
A

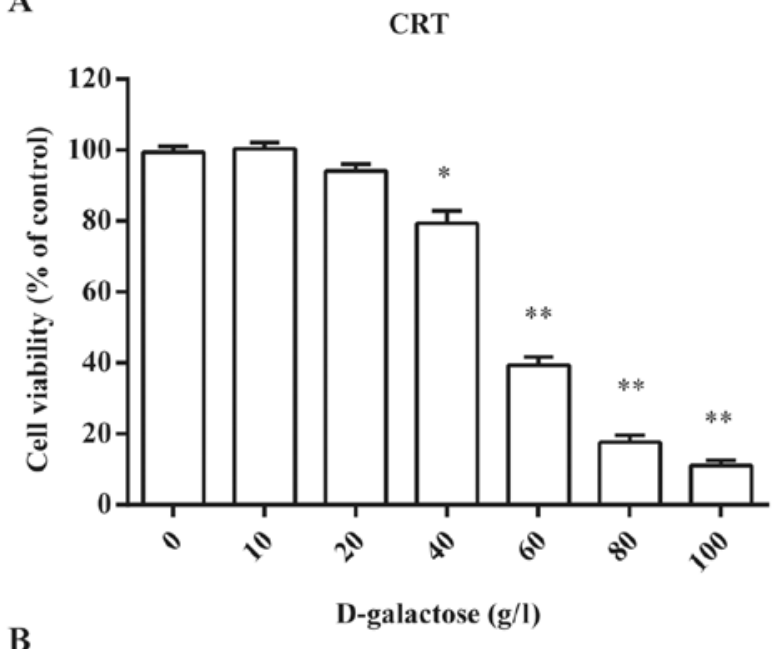

B

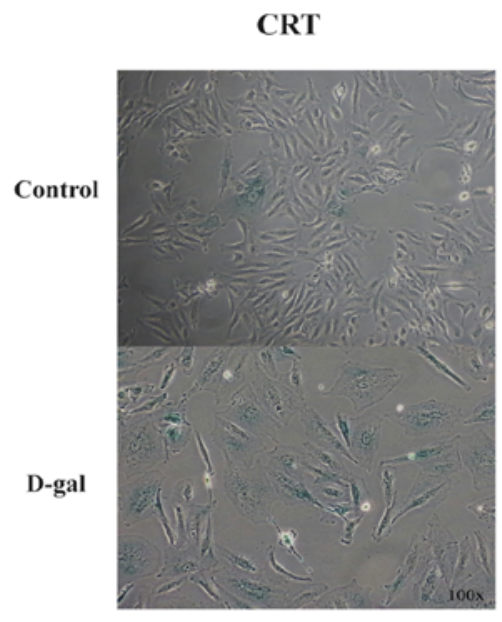

CRT

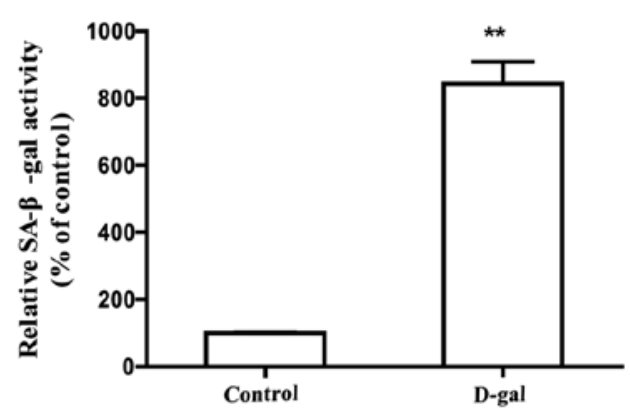

Rat primary astrocytes

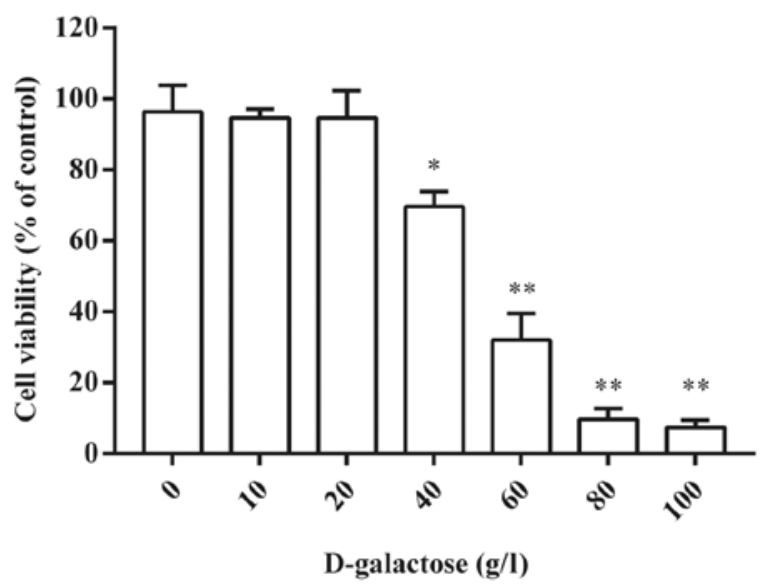

Rat primary astrocytes

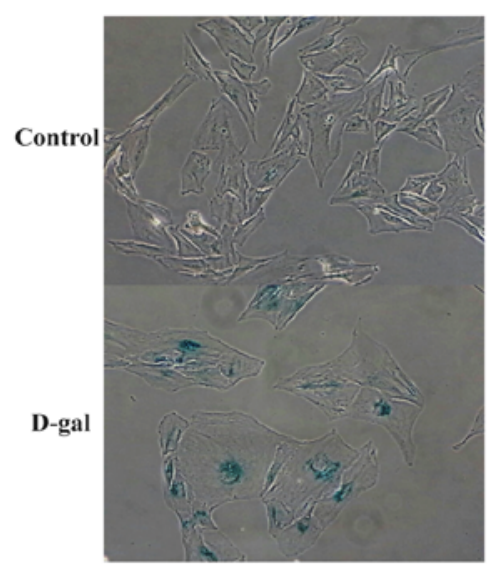

Rat primary astrocytes

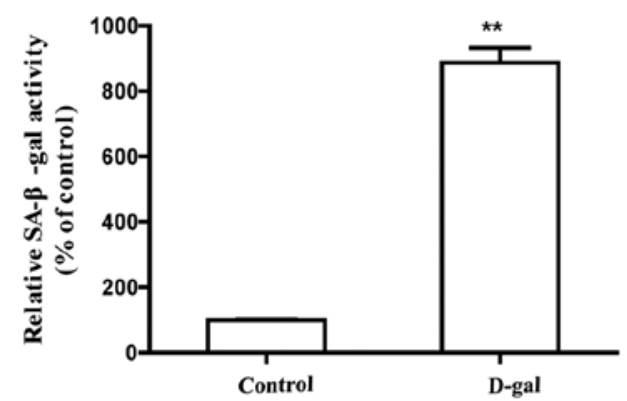

C

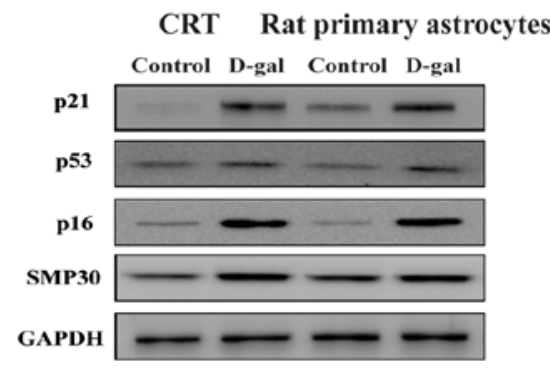

Figure 1. D-gal treatment suppresses cell viability and induces cellular senescence of astrocytic CRT cells and rat primary astrocytes. (A) Astrocytic CRT cells and rat primary cells were incubated with different concentrations of D-gal $(0,10,20,40$ and $60 \mathrm{~g} / \mathrm{l})$ for $72 \mathrm{~h}$. Then, cells were analyzed for their viability. (B) Astrocytic CRT cells and rat primary astrocytes were treated with $50 \mathrm{~g} / 1 \mathrm{D}$-galactose for 5 days, and the percentage of cells expressing senescence-associ ated- $\beta$-galactosidase was determined by light microscopy (top panel) and counting (bottom panel; both magnification, x100). (C) Extracts from non-senescent or senescent (D-gal) astrocytic CRT cells and rat primary astrocytes were assayed for the indicated senescence marker proteins (p16, p21, SMP30 and p53) by western blotting. GAPDH served as loading control. ${ }^{*} \mathrm{P}<0.05$ and ${ }^{* *} \mathrm{P}<0.01$ vs. control group. Three independent experiments were conducted. D-gal, D-galactose; SMP30, senescence marker protein 30. 
A

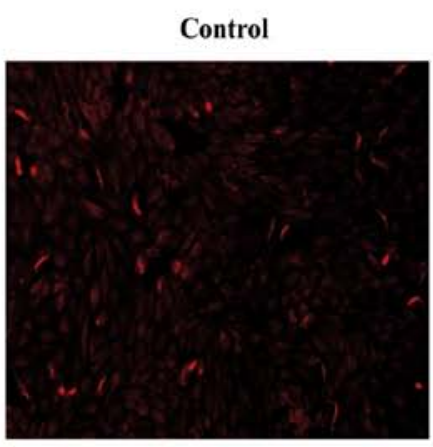

B

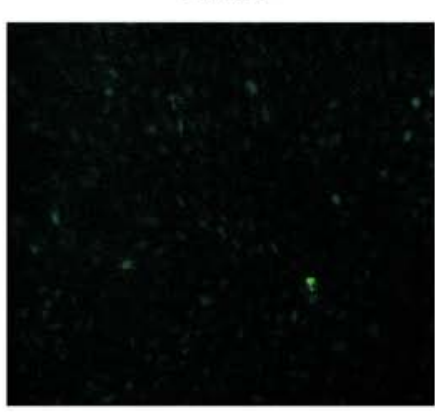

C

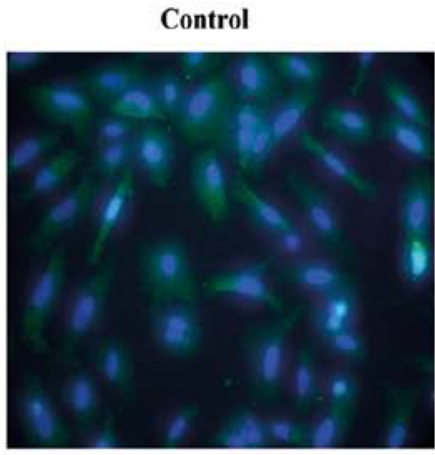

D

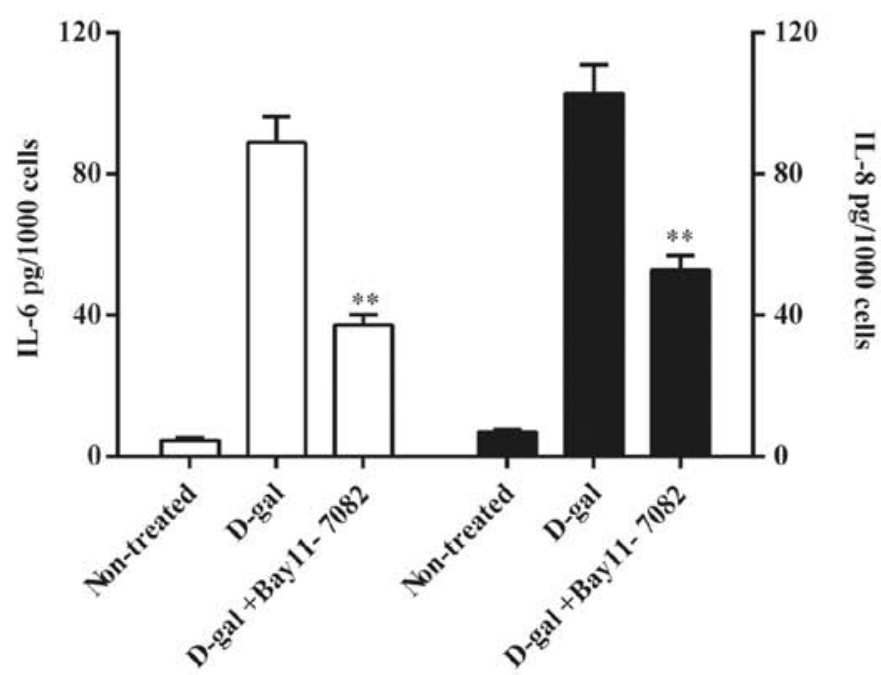

西
D-gal

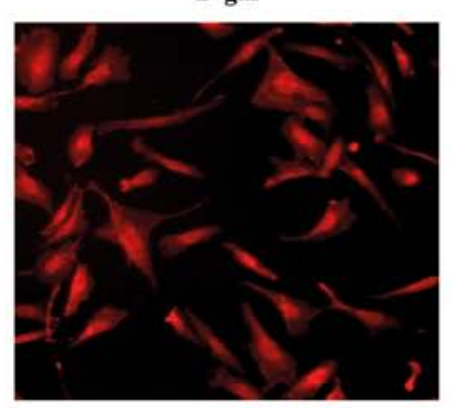

D-gal

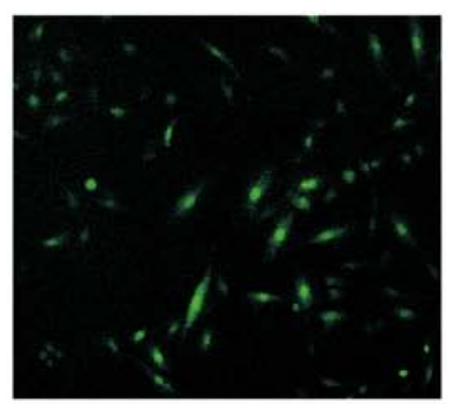

D-gal
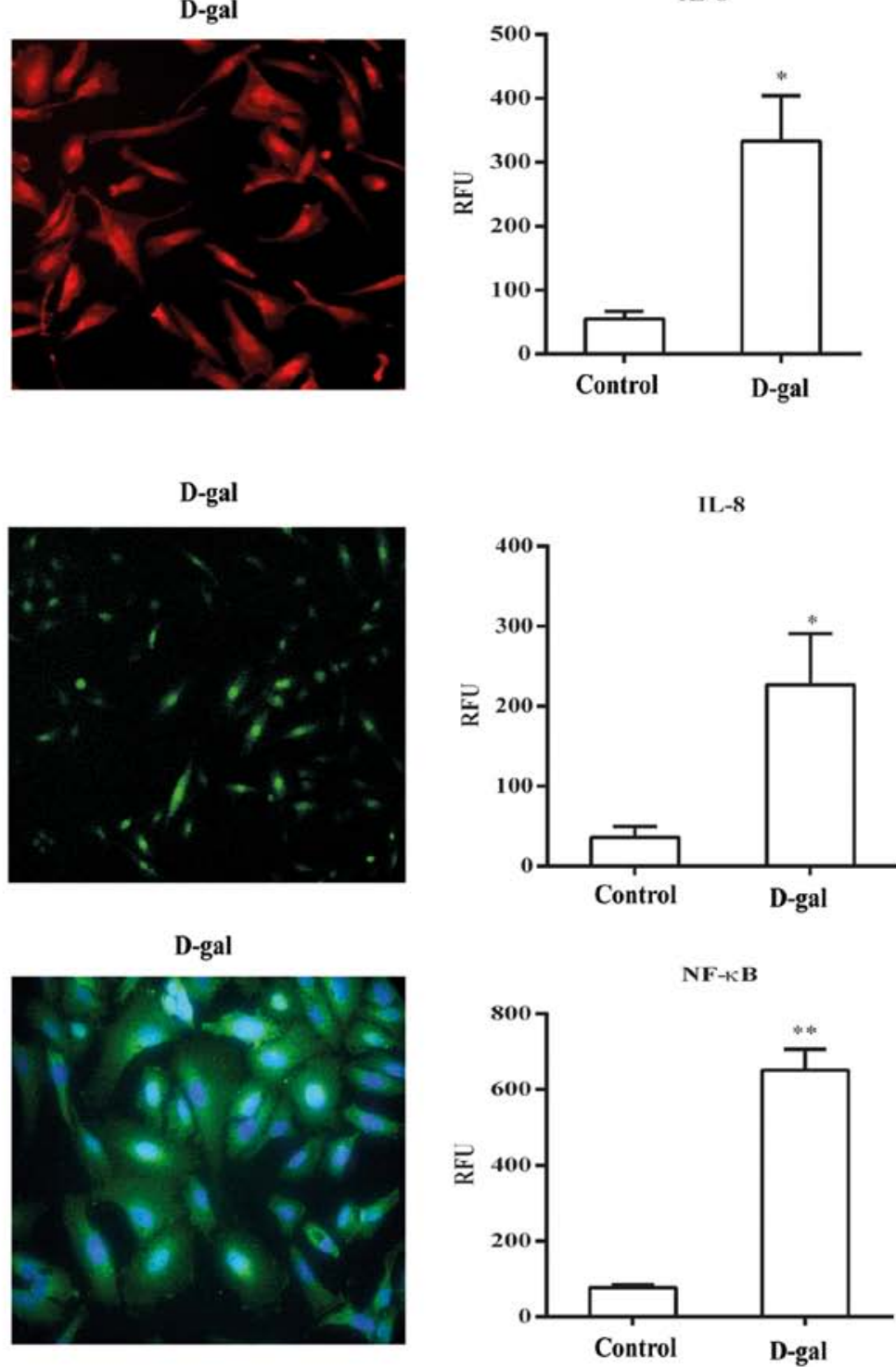

IL-8

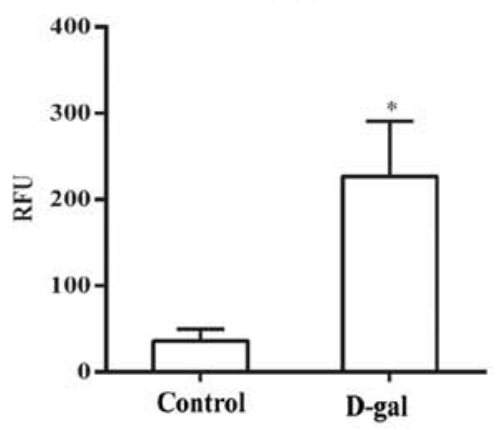


$\mathbf{A}$

U373-MG

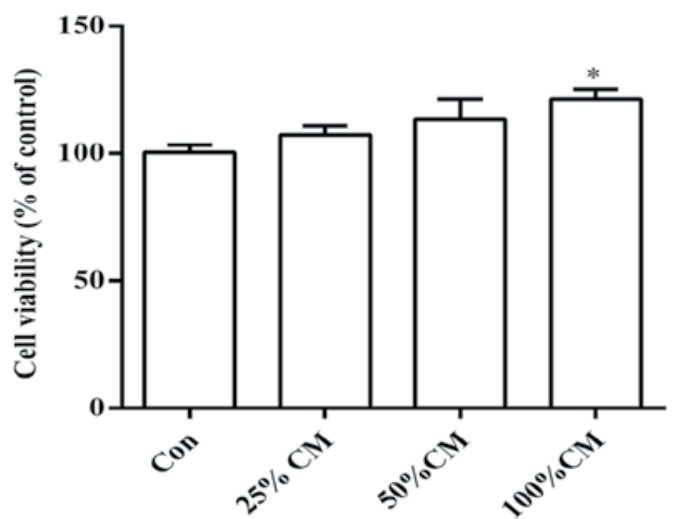

$\mathrm{C}$

$$
\begin{aligned}
& \underset{(0.5 \mathrm{mM})}{\mathrm{TMZ}}+\quad+\quad+ \\
& \begin{array}{llllll}
\text { U373-MG } & \begin{array}{l}
\text { Normal } \\
\text { medium }
\end{array} & 25 \% & 50 \% & 100 \% & \begin{array}{l}
\text { Normal } \\
\text { medium }
\end{array}
\end{array}
\end{aligned}
$$

PARP
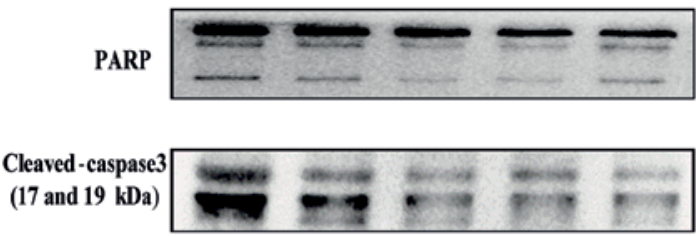

GAPDH

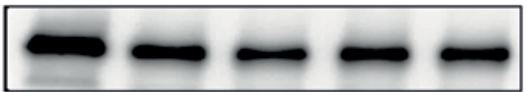

E

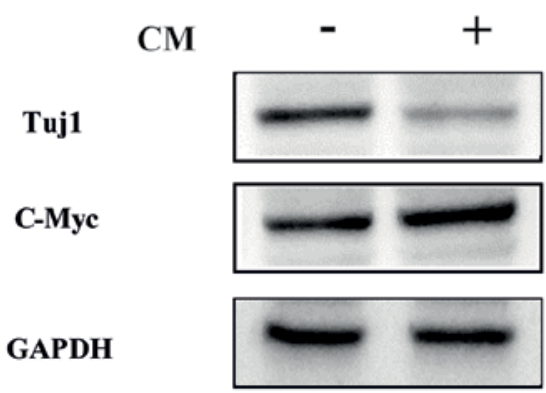

B

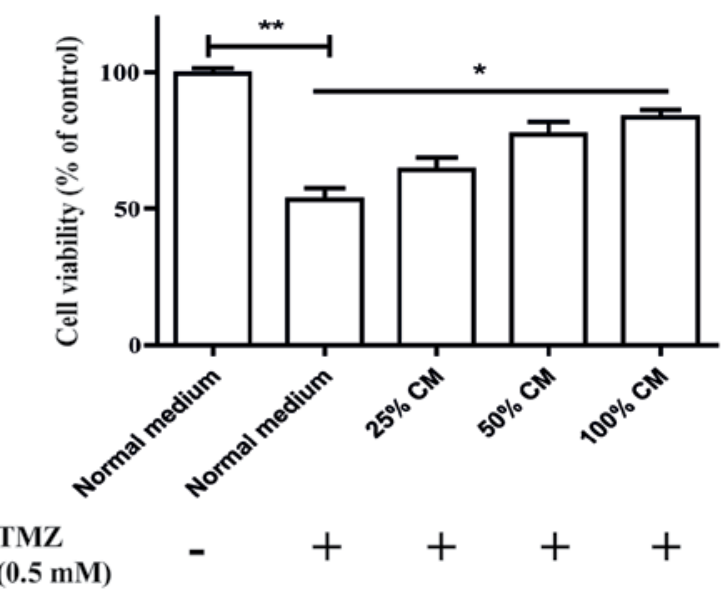

D

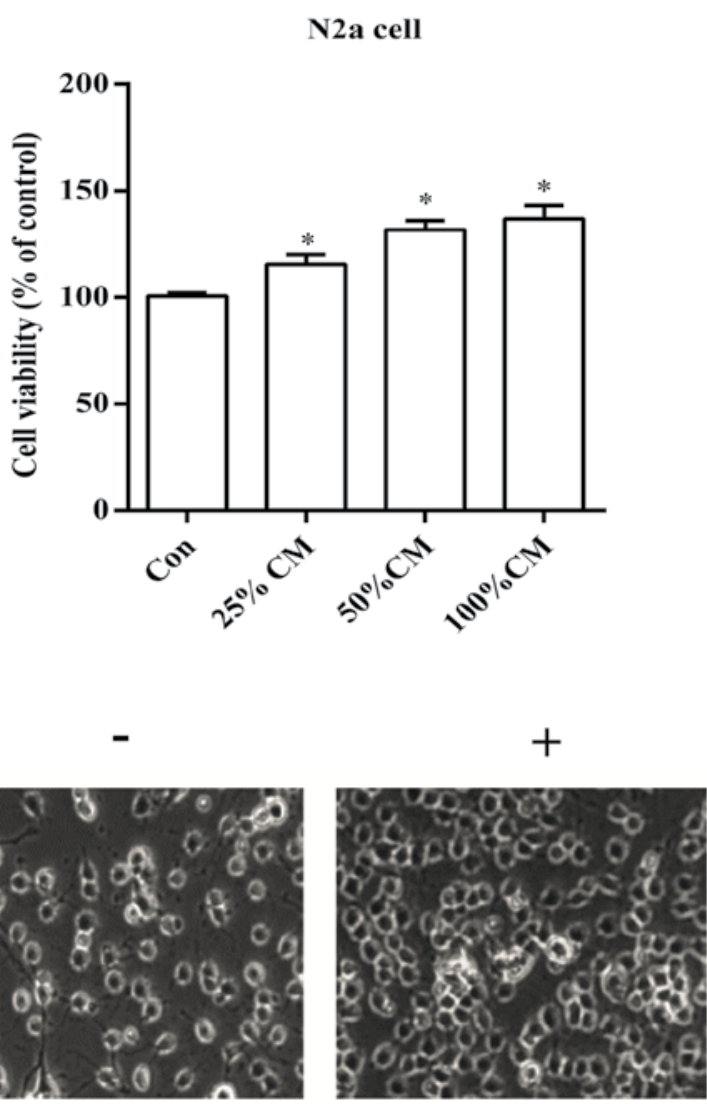

Figure 3. SASP of astrocytic CRT cells promotes brain tumor viability and chemotherapy resistance. (A) U373-MG cells were treated with the indicated concentrations of CM from senescent astrocytic CRT cells, after which cell viability was analyzed by a WST-1 assay. (B) U373-MG cells were treated with normal medium or indicated concentrations of $\mathrm{CM}$ for $24 \mathrm{~h}$, after which cells were plated with fresh medium supplemented with $0.5 \mathrm{mM}$ TMZ for $48 \mathrm{~h}$. Finally, the cell viability was determined by a WST-1 assay. (C) Extracts from non-treated or TMZ treated, CM-treated U373-MG cells and TMZ-treated, were assay for cleaved-caspase 3 and PARP by western blotting. (D) N2a cells were treated with the indicated concentrations of CM from senescent astrocytic CRT cells, then the viability was analyzed by a WST-1 assay. (E) After treatment with CM, protein extracts from N2a cells were analyzed for Tuj1 and c-Myc expression by western blotting for the indicated tumor and neuronal markers; microscopic analysis was also conducted (magnification, $\mathrm{x} 100$ ). GAPDH served as the loading control. ${ }^{\mathrm{P}}<0.05$ and ${ }^{* *} \mathrm{P}<0.01$ vs. control group. Con, control; $\mathrm{CM}$, conditioned medium; PARP, poly (ADP-ribose) polymerase; TMZ, temozolomide; Tuj1, neuron-specific class III $\beta$-tubulin.

presence in senile plaques and neurofibrillary tangles $(28,29)$. Additionally, the accumulation of ROS activates the mitochondrial apoptotic pathway via cytochrome $c$ release (30) and markedly decreased glutamine synthetase expression in the brain of mice (31). Collectively, the majority of studies have reported on mitochondrial damage by ROS and the interaction of AGE-receptor for AGE in the brain (32). Our study herein addressed a novel possibility in vitro: D-galactose might induce brain inflammation caused by senescent astrocytes and the SASP. The SASP involves potent inflammatory cytokines such as IL-6 and IL-8, which may alter tissue environments. This is in agreement with previous reports in epithelial cell 
models $(33,34)$. In summary, our findings reported astrocytic SASP as a potential mechanism by which D-galactose treatment induces brain aging and aging-related pathologies, including the development of brain cancer. Understanding how the SASP is regulated and how it may be prevented is useful in clinical practice. The model described in the present study provided a basis for the screening and development of potential therapeutic strategies to reduce deleterious effects of astrocytic senescence during the normal process of aging.

\section{Acknowledgements}

Not applicable.

\section{Funding}

The present study was supported by the Intelligent Synthetic Biology Center of the Global Frontier Project, funded by the Ministry of Education, Science and Technology (grant no. 2011-0031967).

\section{Availability of data and materials}

All data generated or analyzed during this study are included in this published article.

\section{Authors' contributions}

JH wrote the paper. JH and YY performed the experiments. JH, JX, MS and SK designed the experiments and improved the manuscript. All authors read and approved the manuscript and agree to be accountable for all aspects of the research in ensuring that the accuracy and integrity of any part of the work are appropriately investigated and resolved.

\section{Ethics approval and consent to participate}

Not applicable.

\section{Patient consent to participate}

Not applicable.

\section{Competing interests}

The authors declare that they have no competing interests.

\section{References}

1. Allsopp RC and Harley CB: Evidence for a critical telomere length in senescent human fibroblasts. Exp Cell Res 219: 130-136, 1995.

2. Ito T, Teo YV, Evans SA, Neretti N and Sedivy JM: Regulation of cellular senescence by polycomb chromatin modifiers through distinct DNA damage-and histone methylation-dependent pathways. Cell Rep 22: 3480-3492, 2018.

3. Robinson AR, Yousefzadeh MJ, Rozgaja TA, Wang J, Li X, Tilstra JS, Feldman CH, Gregg SQ, Johnson CH, Skoda EM, et al: Spontaneous DNA damage to the nuclear genome promotes senescence, redox imbalance and aging. Redox Biol 17: 259-273, 2018.

4. Wang W, Li P, Xu J, Wu X, Guo Z, Fan L, Song R, Wang J, Wei L and Teng H: Resveratrol attenuates high glucose-induced nucleus pulposus cell apoptosis and senescence through activating the ROS-mediated PI3K/Akt pathway. Biosci Rep 38: BSR20171454, 2018.
5. Li T, Shi D, Wu Q, Zhang Z, Qu H and Jiang Y: Sodium para-aminosalicylate delays pericarp browning of litchi fruit by inhibiting ROS-mediated senescence during postharvest storage. Food Chem 278: 552-559, 2019.

6. Myrianthopoulos V, Evangelou K, Vasileiou PVS, Cooks T, Vassilakopoulos TP, Pangalis GA, Kouloukoussa M, Kittas C, Georgakilas AG and Gorgoulis VG: Senescence and senotherapeutics: A new field in cancer therapy. Pharmacol Ther 193: 31-49, 2019

7. Sieben CJ, Sturmlechner I, van de Sluis B and van Deursen JM: Two-step senescence-focused cancer therapies. Trends Cell Biol 28: 723-737, 2018.

8. Ovadya Y, Landsberger T, Leins H, Vadai E, Gal H, Biran A Yosef R, Sagiv A, Agrawal A, Shapira A, et al: Impaired immune surveillance accelerates accumulation of senescent cells and aging. Nat Commun 9: 5435, 2018.

9. Shakeri H, Lemmens K, Gevaert AB, De Meyer GRY and Segers VF: Cellular senescence links aging and diabetes in cardiovascular disease. Am J Physiol Heart Circ Physiol 315: H448-H462, 2018.

10. Jeon OH, David N, Campisi J and Elisseeff JH: Senescent cells and osteoarthritis: A painful connection. J Clin Investig 128: 1229-1237, 2018

11. Baar MP, Perdiguero E, Munoz-Canoves P and de Keizer PL: Musculoskeletal senescence: A moving target ready to be eliminated. Curr Opin Pharm 40: 147-155, 2018.

12. Gonzalez-Meljem JM, Apps JR, Fraser HC and MartinezBarbera JP: Paracrine roles of cellular senescence in promoting tumourigenesis. Br J Cancer 118: 1283-1288, 2018.

13. Corlier F, Hafzalla G, Faskowitz J, Kuller LH, Becker JT, Lopez OL, Thompson PM and Braskie MN: Systemic inflammation as a predictor of brain aging: Contributions of physical activity, metabolic risk, and genetic risk. Neuroimage 172: 118-129, 2018.

14. Salminen A, Ojala J, Kaarniranta K, Haapasalo A, Hiltunen M and Soininen $\mathrm{H}$ : Astrocytes in the aging brain express characteristics of senescence-associated secretory phenotype. Eur J Neurosci 34: 3-11, 2011.

15. Lu J, Wu Dm, Zheng Y, Hu B and Zhang Zf: Purple Sweet Potato Color Alleviates D-galactose-induced brain aging in old mice by promoting survival of neurons via PI3K pathway and inhibiting cytochrome c-mediated apoptosis. Brain Pathol 20: 598-612, 2010.

16. Cui X, Wang L, Zuo P, Han Z, Fang Z, Li W and Liu J: D-Galactose-caused life shortening in Drosophila melanogaster and Musca domestica is associated with oxidative stress. Biogerontology 5: 317-325, 2004.

17. Shwe T, Pratchayasakul W, Chattipakorn $\mathrm{N}$ and Chattipakorn SC: Role of D-galactose-induced brain aging and its potential used for therapeutic interventions. Exp Gerontol 101: 13-36, 2018.

18. Choi C, Xu X, Oh JW, Lee SJ, Gillespie GY, Park H, Jo H and Benveniste EN: Fas-induced expression of chemokines in human glioma cells: Involvement of extracellular signal-regulated kinase $1 / 2$ and p38 mitogen-activated protein kinase. Cancer Res 61: 3084-3091, 2001.

19. Choi C, Kutsch O, Park J, Zhou T, Seol DW and Benveniste EN: Tumor necrosis factor-related apoptosis-inducing ligand induces caspase-dependent interleukin-8 expression and apoptosis in human astroglioma cells. Mol Cell Biol 22: 724-736, 2002.

20. Bhat R, Crowe EP, Bitto A, Moh M, Katsetos CD, Garcia FU, Johnson FB, Trojanowski JQ, Sell C and Torres C: Astrocyte senescence as a component of alzheimer's disease. PLoS One 7: e45069, 2012.

21. Akinyeke T, Matsumura S, Wang X, Wu Y, Schalfer ED, Saxena A, Yan W, Logan SK and Li X: Metformin targets c-MYC oncogene to prevent prostate cancer. Carcinogenesis 34: 2823-2832, 2013.

22. Coppe JP, Desprez PY, Krtolica A and Campisi J: The senescence-associated secretory phenotype: The dark side of tumor suppression. Annu Rev Pathol 5: 99-118, 2010.

23. Orjalo AV, Bhaumik D, Gengler BK, Scott GK and Campisi J: Cell surface-bound IL-1alpha is an upstream regulator of the senescence-associated IL-6/IL-8 cytokine network. Proc Natl Acad Sci USA 106: 17031-17036, 2009.

24. Davalos AR, Coppe JP, Campisi J and Desprez PY: Senescent cells as a source of inflammatory factors for tumor progression. Cancer Metastasis Rev 29: 273-283, 2010.

25. Le Duff M, Gouju J, Jonchère B, Guillon J, Toutain B, Boissard A, Henry C, Guette C, Lelièvre $\mathrm{E}$ and Coqueret $\mathrm{O}$ : Regulation of senescence escape by the cdk4-EZH2-AP2M1 pathway in response to chemotherapy. Cell Death Dis 9: 199, 2018. 
26. Cui X, Zuo P, Zhang Q, Li X, Hu Y, Long J, Packer L and Liu J: Chronic systemic D-galactose exposure induces memory loss, neurodegeneration, and oxidative damage in mice: Protective effects of R-alpha-lipoic acid. J Neurosci Res 84: 647-654, 2006.

27. Lu J, Zheng YL, Wu DM, Luo L, Sun DX and Shan Q: Ursolic acid ameliorates cognition deficits and attenuates oxidative damage in the brain of senescent mice induced by D-galactose. Biochem Pharmacol 74: 1078-1090, 2007.

28. Liu R, Zhang TT, Zhou D, Bai XY, Zhou WL, Huang C, Song JK, Meng FR, Wu CX, Li L and Du GH: Quercetin protects against the $A \beta(25-35)$-induced amnesic injury: Involvement of inactivation of rage-mediated pathway and conservation of the NVU. Neuropharmacology 67: 419-431, 2013.

29. Xing Z, He Z, Wang S, Yan Y, Zhu H, Gao Y, Zhao Y and Zhang L: Ameliorative effects and possible molecular mechanisms of action of fibrauretine from Fibraurea recisa Pierre on d-galactose $/ \mathrm{AlCl}_{3}$-mediated Alzheimer's disease. RSC Advances 8: 31646-31657, 2018.

30. Kumar A, Prakash A and Dogra S: Naringin alleviates cognitive impairment, mitochondrial dysfunction and oxidative stress induced by D-galactose in mice. Food Chem Toxicol 48: 626-632, 2010.
31. Zhang XL, An LJ, Bao YM, Wang JY and Jiang B: D-galactose administration induces memory loss and energy metabolism disturbance in mice: Protective effects of catalpol. Food Chem Toxicol 46: 2888-2894, 2008.

32. Ali T, Badshah H, Kim TH and Kim MO: Melatonin attenuates D-galactose-induced memory impairment, neuroinflammation and neurodegeneration via RAGE/NF- $\mathrm{KB} / \mathrm{JNK}$ signaling pathway in aging mouse model. J Pineal Res 58: 71-85, 2015.

33. Parrinello S, Coppe JP,Krtolica A and Campisi J: Stromal-epithelial interactions in aging and cancer: Senescent fibroblasts alter epithelial cell differentiation. J Cell Sci 118: 485-496, 2005.

34. Laberge RM, Awad P, Campisi J and Desprez PY: Epithelial-mesenchymal transition induced by senescent fibroblasts. Cancer Microenviron 5: 39-44, 2012. Attribution-NonCommercial-NoDerivatives 4.0 International (CC BY-NC-ND 4.0) License. 